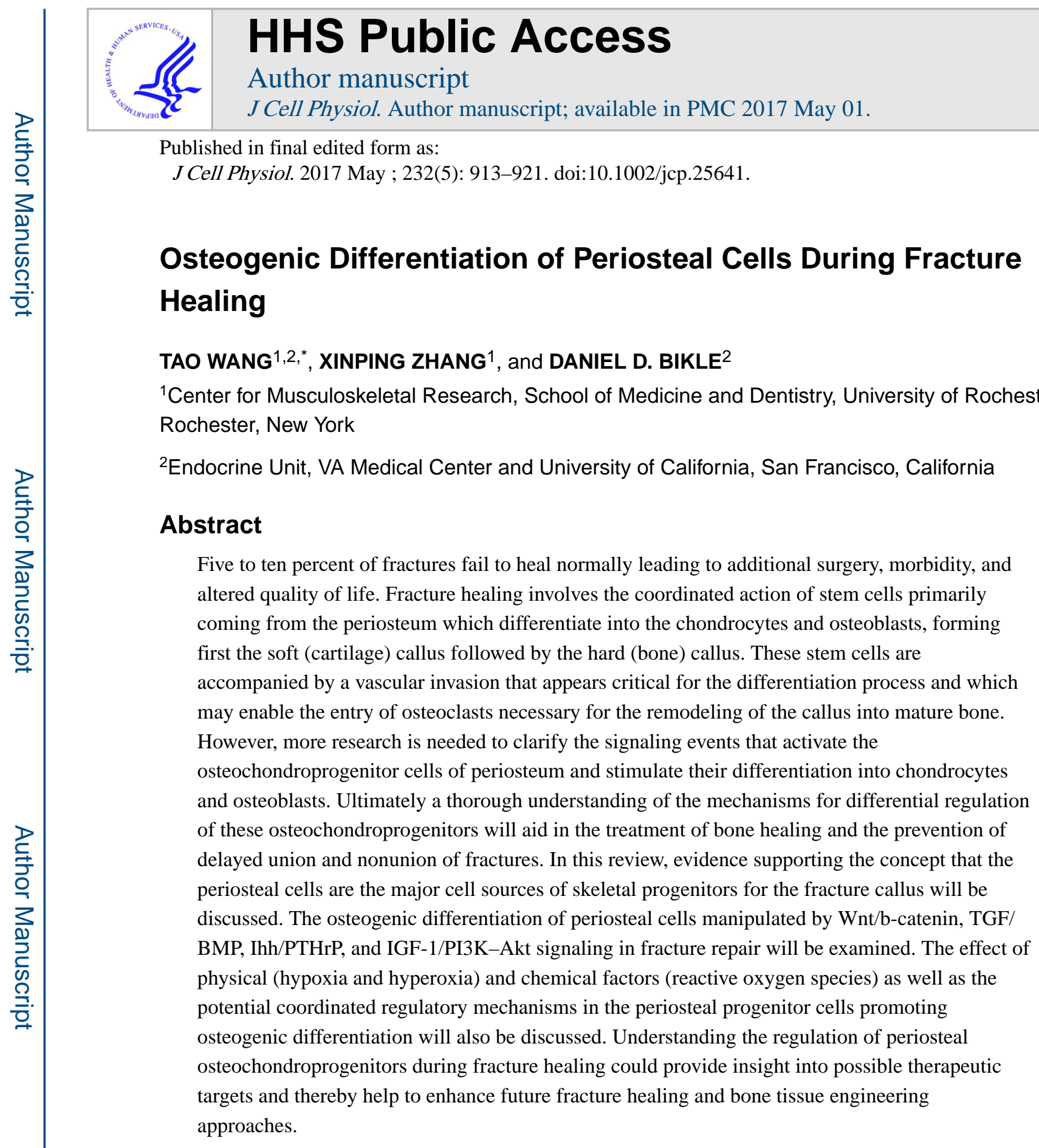

\title{
Orthopaedic trauma
}

In the United States, 5.6 million fractures occur per year, which corresponds to an incidence of $2 \%$ of the US population. Complicated healing such as nonunion, malunion, osteomyelitis, and chronic pain represent 5-10\% of the 5.6 million fractures (Praemer et al., 1992). These conditions are often chronic, and the associated functional and psychosocial

\footnotetext{
"Correspondence to: Tao Wang, Center for Musculoskeletal Research, Orthopaedics and Rehabilitation, University of Rochester, 601 Elmwood Avenue, Box 665, Room 1-7554, Rochester, NY 14642. taowang75@yahoo.com.

Conflicts of interest: The authors declare that there is no conflict of interests regarding the publication of this paper. The content is solely the responsibility of the authors.
} 
morbidity cause exponentially more burden due to the need for surgical intervention, protracted medical care, and loss of productivity, leading to a high level of anxiety and frustration both for the patient and surgeon (Lerner et al., 1993).

\section{The biology of fracture healing}

A complex coordination among inflammatory cells, stem cells, osteoblasts, chondrocytes, osteoclasts, and endothelial cells with surrounding pericytes, cytokines and growth factors is involved in the cellular and molecular events during fracture healing. The initial event in the fracture healing process is the inflammatory phase and subsequent hematoma formation where cellular signaling mechanisms work via inflammation and chemotaxis to attract the cells necessary to initiate the healing process. Many sources of skeletal progenitors have been proposed to participate in bone repair, including the local bone marrow, endosteum, muscle and adipose tissues surrounding fractured bone, blood vessel walls, as well as cells brought to the injury site via blood vessels. But these cells recruited systemically are minimal contributors to cartilage and bone, but give rise mostly to inflammatory cells and osteoclasts (Rieger et al., 2005; Dominici et al., 2008). Periosteum covers most of the external surface of bone and is composed of two distinct layers. The outer more "fibrous" layer of periosteum is composed of fibroblasts, collagen, and elastin fibers (Dwek, 2010). The inner "cambium" layer, positioned in direct contact with the bone surface, contains adult mesenchymal progenitor cells, differentiated osteogenic progenitor cells and osteoblasts, (Aubin and Triffitt, 2002) fibroblasts (Squier et al., 1990), sympathetic nerves (Hohmann et al., 1986) and endothelial pericytes (Diaz-Flores et al., 1992). Periosteum contains osteochondroprogenitor cells that participate in bone and cartilage formation during normal development and fracture healing (Nakahara et al., 1990; Colnot, 2009). Many markers have been utilized to identify mouse osteochondroprogenitor cells from periosteum including Paired-related homeobox gene-1 (Prx-1) (Kawanami et al., 2009), Sox9 (Akiyama et al., 2005), alpha smooth muscle actin (aSMA) (Matthews et al., 2014), fibroblast growth factor receptor 2 (FGFR2), and Dermo1 (Yu et al., 2003). Mx1-Cre also labeled cells in the periosteum, although these cells contributed only to osteoblastic progenitors and not chondrocytes during microfracture healing in the femur (Park et al., 2012). Prx-1 is expressed in the early limb bud mesenchyme in mouse embryos and that Cre recombinase activity is present in all mesenchymal cells, including osteochondroprogenitors. (Martin and Olson, 2000) Mice homozygous for a mutant Prx-1 allele exhibited the loss or malformation of facial, limb, and vertebral skeletal structures because of a defect in the formation and growth of chondrogenic and osteogenic precursors (Martin et al., 1995). A 2.4 kb Prx-1 promoter directing the transgene expression is extinguished in the condensing mesenchyme and chondrocytes, and its expression is confined to the periosteum and tendons of the limbs at E15.5. Therefore, the $2.4 \mathrm{~kb}$ Prx-1 promoter would be useful for expressing genes in the osteochondroprogenitor cells of adult periosteum (Kawanami et al., 2009). Sox9, a transcription factor with a high-mobility group DNA-binding domain, is expressed in all osteochondroprogenitor cells and a variety of tissues, including central nervous system, neural crest, intestine, pancreas, testis, and endocardial cushions, and plays a crucial role in cell proliferation and differentiation. Sox9-expressing osteochondroprogenitors is the subset population of Prx1-expressing undifferentiated limb bud mesenchyme (Akiyama et al., 
2005). Alpha smooth muscle actin (aSMA) is a marker of pericytes and myofibroblastic cells that identifies mesenchymal progenitor cells with proliferative and multi-lineage differentiation potential in bone marrow stromal cell (Kalajzic et al., 2008), periodontium (Roguljic et al., 2013) and osteochondroprogenitors in periosteum (Matthews et al., 2014). The aSMA-labeled population can originate from periosteum and expand as well as differentiate toward the osteogenic and chondrogenic lineages during fracture healing (Matthews et al., 2014). FGFR2 and Dermo1 are expressed at high levels in condensed mesenchyme that will give rise to cartilage and bone and later in the perichondrial and periosteal tissues that give rise to osteoblasts (Ornitz and Marie, 2002; Yu et al., 2003).

To investigate the lineage of the periosteal cells participating in fracture healing, we generated and analyzed the process of tibial fracture healing with mice expressing tamoxifen inducible Prx1-CreER-eGFP ((Tg(Prrx1-cre/ERT2,-EGFP) $\left.{ }^{1 \mathrm{Smkm}}\right)$ bred with mice

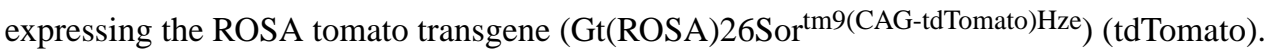
Following tamoxifen administration, these mice express, in the osteochondroprogenitors of periosteum, CreER and fluorescent tdTomato probe under the control of a mouse $2.4 \mathrm{~kb}$ Prx 1 promoter (Wang T, presented at the ORS 2015 Annual Meeting, Las Vegas, Nevada, March 24-28, 2015). The periosteal reaction that occurred after tibial fracture was marked by the thickening of the cambial layer and the activation of the osteochondroprogenitors (Fig. 1A and A1) as a result of increased proliferation of these progenitor cells (Fig. 1B). A set of wedge-shaped areas of intramembranous bone formation was initiated immediately adjacent to the distal edges of the periosteal reaction, while adjacent to the periosteum of the central areas was where cartilage was forming. The osteochondroprogenitors originating from the periosteum migrate into the early fracture hematoma and eventually differentiate into osteoblasts and chondrocytes to participate in fracture healing (Fig. 1C-F). The cartilage tissue disappeared by 21 days, while the tdTomato labeled cells remained on the surface of trabecular bone and within the trabecular bone structure in the calcified cartilage region (Fig. $1 \mathrm{G}$ and $\mathrm{H}$ ). These labeled cells could still be observed within the lamellar and cortical bone matrices 60 days after fracture (data not shown). These results indicated that cells originating in the periosteum adjacent to the distal edges of the periosteal reaction directly differentiated into osteoblasts. Some periosteal cells migrated into the hematoma between the fracture ends and differentiated into chondrocytes to form the soft callus during fracture. During the remodeling stage, these cells could survive and were embedded in the bone matrix of the hard callus to become osteocytes. Therefore, the role of periosteum in fracture healing is to provide chondrogenic and osteogenic cells for both endochondral and intramembranous bone formation. Moreover, many labeled cells were detected on the surface of newly formed vascular cavities (Fig. 1I and J). These cells might be endothelial pericytes located on the abluminal wall of capillaries in the callus. Endothelial pericytes can originate from the periosteum and contribute significantly to callus neovascularization during fracture repair (Diaz-Flores et al., 1992). Vascular formation is critical for the differentiation process and which may enable the entry of osteoclasts necessary for the remodeling of the callus into mature bone. Thus, stem cells from the periosteum are involved in all phases of fracture healing and play an essential role in the healing process of fractures. Our data are consistent with other lineage analyses showing that the major sources of progenitor cells differentiating into the chondrocytes and osteoblasts producing bone and 
cartilage at the fracture site have largely originated from the periosteum (Zhang et al., 2005; Colnot, 2009; Yang et al., 2014). Osteochondroprogenitors from the periosteum are essential for the healing process of fractures. However the differential regulation of periosteal cell differentiation to chondrocytes and osteoblasts during fracture healing is still not fully understood. Methods to increase the recruitment of periosteal progenitors committed to the osteoblast lineage in fracture sites could improve fracture healing at earlier stages of fracture healing. Understanding this osteoblastic differentiation of periosteal cells not only provides mechanistic insight into the osteogenic capacity of the periosteum, but could also offer strategies to recruit the endogenous osteogenic cell sources for bone repair and accelerate bone fracture healing.

\section{Signaling Pathways in the Osteogenic Differentiation of Periosteal Cells During Fracture Healing}

\section{Wnt/b-catenin signaling pathway}

The Wnt/b-catenin pathway regulates multiple biological events during embryonic development and fracture repair, such as osteoblast differentiation and bone formation (Macsai et al., 2008; Jin et al., 2015). Several intracellular pathways are induced on activation of the Wnt receptor, such as the b-catenin-dependent canonical pathway and the [beta]-catenin-independent noncanonical pathways (planar cell polarity pathway and $\mathrm{Ca}^{2} \mathrm{~b}$ mediated pathway). The canonical $\mathrm{Wnt} / \mathrm{b}$-catenin signaling pathway is initiated by the interaction of Wnt ligands, such as Wnt 1,3a, and 8, with their cognate receptor complex, which consists of a seven-transmembrane domain receptor of the Frizzled (Fzd) family of receptors, and a low density lipoprotein receptor-related protein 5/6 (LRP5/6) coreceptor. In the presence of a Wnt ligand binding to LRP5/6 and Fzd, Dsh is phosphorylated and inhibits GSK3b from phosphorylating $b$ catenin in the cytoplasm, enabling b-catenin to translocate to the nucleus where it interacts with members of the T-cell factor/lymphocyte enhancer factor (TCF/LEF) family to activate Wnt target genes (Mao et al., 2001; Clevers, 2006; Silkstone et al., 2008; Kim et al., 2013) (Fig. 2). Binding of b-catenin displaces transcriptional co-repressors bound to TCF/LEF and recruits transcriptional co-activators, for example, the histone acetylase p300/CBP and CREB (cAMP response element-binding protein), which act through the remodeling of chromatin surrounding TCF binding sites (Levy et al., 2004). Functional b-catenin-TCF/LEF regulatory element responsive to canonical WNT signaling resides in the promoter of the Runt Related Transcription factor 2 (Runx2) gene (97 to 93) and is crucial for the activation of endogenous Runx2, which controls osteoblast differentiation and skeletal development (Gaur et al., 2005).

Increased b-catenin activity is shown in osteoblasts lining the periosteum throughout fracture healing in mice. During fracture repair, canonical Wnt/b-catenin pathway is the dominant mechanism for regulating osteoblast differentiation. Wnt/b-catenin signaling inhibits multipotent mesenchymal stem cells from differentiating into adipocytes (Ross et al., 2000) and commits progenitor cells to the osteoblast lineage(Gaur et al., 2009). Early osteoblast lineage cells lacking b-catenin are blocked in osteoblast differentiation and develop a chondrocyte phenotype instead (Hill et al., 2005; Chen et al., 2007). 
Wnt/b-catenin signaling has been shown to have opposite osteogenic effects on undifferentiated and differentiated mesenchymal cells. Wnt3a induces osteogenesis in mature calvarial osteoblasts in a dose dependent manner. Conversely, Wnt3a or constitutively activated b-catenin, inhibits the osteogenic differentiation of undifferentiated mesenchymal cells and juvenile calvarial cells in a dose-dependent fashion (Quarto et al., 2010). Prefracture lithium treatment, which activates the canonical WNT signaling through inhibition of GSK3b (Zhang et al., 2003), inhibits the repair process, but post-fracture treatment enhances bone healing (Chen et al., 2007). These studies demonstrate that Wnt/bcatenin signaling has a different role in undifferentiated mesenchymal cells and committed osteogenic progenitor cells. This implies that the Wnt/b-catenin signaling stimulants promoting fracture healing should be utilized only after mesenchymal cells are committed to the osteoblast lineage.

\section{Transforming growth factor-beta (TGF-b)/bone morphogenic protein (BMP) signaling}

Transforming growth factor-beta (TGF-b)/bone morphogenic protein (BMP) signaling is involved in a vast majority of cellular processes. TGF-b/BMPs have been widely recognized in the roles of bone formation during mammalian development and exhibit crucial regulatory functions in cell proliferation and differentiation. Signaling transduction by TGF-b/BMPs is specifically through both canonical Smad-dependent pathways (TGF-b/BMP ligands, receptors and Smads) and non-canonical Smad-independent signaling pathway (e.g., p38 mitogen-activated protein kinase pathway, p38 MAPK (Chen et al., 2012). In general, signaling is initiated with ligand-induced oligomerization of serine/threonine receptor kinases and phosphorylation of the cytoplasmic signaling molecules Smad2 and Smad3 for the TGF-b signaling pathway, or Smad1/5/9 for the bone morphogenetic protein (BMP) pathway. Activated Smads form a complex with Smad4 and then translocate into the nucleus where they recognize the Smad-binding element (SBE) to trigger osteogenic transcriptional regulator Runx2 expression (Horbelt et al., 2012). Moreover, in certain contexts, TGF-b/ BMPs also initiate the non-Smad-dependent signaling pathway (p38 MAPK) to transmit signal by activating TGF-b activation kinase1 (TAK1), which phosphorylates MKK3/6. Activated p38 phosphorylates Runx2 and boosts its transcriptional potential (RodriguezCarballo et al., 2016) (Fig. 3).

Immunohistochemical staining has demonstrated that TGF-b is highly synthesized in the periosteum during fracture healing and enhances the proliferation and differentiation of periosteal mesenchymal cells, increases the production of extracellular matrix and is chemotactic to bone cells (Joyce et al., 1990). Mice carrying tissue-specific removal of TGFbRI driven by Dermo1-Cre and the removal of TGFbR2 driven by Prx-Cre results in defects in development of the long bones and joints (Seo and Serra, 2007; Matsunobu et al., 2009). TGF-b cooperates with Wnt signaling in osteoblast differentiation, activates b-catenin signaling via ALK5, Smad3, PKA, and PI3K pathways, and modulates osteoblastogenesis via ALK5, PKA, and JNK pathways in hMSCs (Zhou, 2011).

BMPs belong to the transforming growth factor $\mathrm{b}$ (TGFb) gene superfamily. BMPs are pleiotropic morphogens and play a critical role in regulating growth, differentiation, and apoptosis of various cell types, including osteoblasts, chondroblasts, neural cells, and 
epithelial cells (Sakou, 1998). BMP heterodimers, such as BMP-4/-7 and BMP-2/-7 have been shown to enhance osteoinductive activity regulating differentiation and proliferation of mesenchymal cells to osteoblasts in vitro and in vivo (Israel et al., 1996). In the early stages of fracture repair, the expression of BMP-2/-4 and BMP-7 (OP-1) is strongly induced in the thickened periosteum near the fracture ends, which coincides with an enhanced expression of the BMP type II receptor (BMPR-II). BMP-2/-4/-7 and BMPR-II are also present in various types of chondrocytes in endochondral bone as well as in osteoblasts within newly formed trabecular bone (Onishi et al., 1998). Endogenous BMP-2 plays a crucial role in the periosteum-mediated bone/cartilage callus formation, and deletion of BMP-2 resulted in over $90 \%$ of the mutant mesenchymal progenitors remaining undifferentiated (Wang et al., 2011). The phenotype in the Prx1-Cre Bmp-2 knockout fracture model showed that mesenchymal progenitors at the fracture site remained undifferentiated and did not differentiate into osteoblasts or chondrocytes in the absence of BMP-2. A complete absence of a bridging callus left the ends of the fractured bone a fair distance apart without new chondrogenesis. But BMP-4 and Bmp-7 were present at comparable levels in mice with and without BMP2 in the early stages of fracture healing indicating that BMP2 is specifically required for the initiation of bone healing (Tsuji et al., 2006).

Treatment of the multipotent mesenchymal cell line C3H10T1/2 with BMP-2 and BMP-7 promoted osteoblast differentiation, induced osteoblast-related markers and demonstrated positive ALP activity. Untreated samples had extremely low levels of osteoblast differentiation markers (Wang et al., 1993). Deleting BMP-2 in immature osteoblasts using 3.6 Col1a1-Cre, a Bmp2-cKO ${ }^{\mathrm{ob}}$ model, resulted in a failure of osteoblasts to differentiate to a mineralizing state in vivo (Yang et al., 2013). This study also showed that 3.6 Col1a1-Cre activity was mainly located in several layers of the periosteum and associated tendons, whereas no Cre activity was detected in the vast majority of the bone marrow. This model is consistent with previously described data indicating that the periosteum provides early osteoblasts but also shows the direct role of BMP-2 in the differentiation of preosteoblasts into mature osteoblasts (Yang et al., 2013). BMP-2-induced osteogenic differentiation of mesenchymal cells might be initiated via the upregulation of the osteogenic transcriptional regulators Runx2 and Osx consistent with BMP2 expression peaking 3.6-4 fold over basal expression at 1 day after fracture (Cho et al., 2002; Ryoo et al., 2006).

p38 MAPK signaling not only plays an important signaling role in bone formation but also orchestrates injury or stress-induced responses. TAK1 is identified as a mitogen-activated kinase kinase kinase (MAP3K) activated by TGF-b/BMPs; it has been characterized as a key regulator in inflammatory and immune signaling pathways (Sakurai, 2012). Therefore, the activation of p38 MAPK signaling also leads to the production of inflammatory cytokines and their signal transduction. The interaction between p38 MAPK and pro-inflammatory cytokines is important in controlling life and death signaling cascades in osteoblasts and chondrocytes (Waki et al., 2016). Cox-2 is a major player in inflammatory reactions. Cox-2 deletion in mesenchymal progenitors using Prx1-cre is associated with a marked reduction of intramembraneous and endochondral bone repair, leading to accumulation of poorly differentiated mesenchyme and immature cartilage in periosteal callus. It suggests that Cox-2 is one of the important downstream mediators of BMPs and coordinates with BMPs in the differentiation of mesenchymal progenitors in periosteum (Huang et al., 2014). 
BMPs coordinate with several signaling pathways in the regulation of osteoblast differentiation. TGF-b1 strongly enhances ectopic bone formation induced by BMP-2, resulting in the number of osteoblasts being twofold greater and bone volume being five-fold greater than that induced by BMP-2 alone (Tachi et al., 2011). Wnt/beta-catenin transactivation of BMP2 transcription is directly mediated through the Tcf/Lef response elements in the BMP2 promoter. This study suggests that Wnt signaling is an upstream regulator of BMP signaling in osteoblasts (Zhang et al., 2013).

\section{Indian hedgehog-PTHrP signaling}

Both the Indian hedgehog (Ihh) and the parathyroid hormone receptor (PTHR) signaling pathways closely interact and take part in bone and cartilage development as well as fracture repair. Ihh is expressed by "prehypertrophic chondrocytes," which are chondrocytes in transition between the proliferative and hypertrophic states. Hedgehog (Hh) signaling regulates aspects of chondrocyte maturation during fetal and early postnatal skeletogenesis and post-natal bone fracture healing (Le et al., 2001). There are three Hh ligands in vertebrates: Sonic hedgehog (Shh), Indian hedgehog (Ihh), and Desert hedgehog (Dhh). Shh and Ihh, a homolog of Shh, have similar roles in development and phenocopy each other. An Ihh-patched-parathyroid hormone-related protein (PTHrP) auto-regulatory loop modulates chondrocyte maturation. Ihh expression in the prehypertrophic chondrocytes of the growth plate triggers expression of PTHrP in the chondrocytes of the resting zone. PTHrP then binds to the PTH/PTHrP receptor in the prehypertrophic chondrocytes, inhibiting expression of endogenous Ihh through a negative feedback loop and blocking chondrocyte hypertrophic differentiation (Vortkamp et al., 1996).

The Ihh target genes Ptc and Gli are predominantly expressed in the perichondrium rather than in the cartilage itself. Therefore the primary target tissue of Ihh-PTHrP signaling is likely to be the perichondrium of embryos. Perichondrium is a layer of dense irregular connective tissue which surrounds the cartilage of developing bone; once vascularized, the perichondrium becomes the periosteum (Dwek, 2010). It is reasonable to believe that IhhPTHrP signaling may influence the process of chondroblast differentiation in the periosteum during fracture healing. Ihh can induce differentiation of adjacent perichondrial cells into bone-forming osteoblasts (Yamaguchi et al., 2000). Ihh/compared to the $\mathrm{Ihh}^{+/+}$mice displayed reduced chondrocyte hypertrophy and complete absence of the expression levels and localization of RunX2 in periosteum or perichondral tissue, trabecular and cortical bone (St-Jacques et al., 1999). Using N-terminal Shh peptide (ShhN), a strong agonist for all $\mathrm{Hh}$ pathways, one could effectively promote osteogenic and chondrogenic differentiation of periosteum-callus-derived mesenchymal stem cells (PCDSCs) in vitro and induce bone formation in vivo. Blocking Hh signaling in transgenic mice by deleting Smoothened (Smo) at the onset of bone autograft repair markedly reduced osteogenic differentiation of isolated PCDSCs and further resulted in a near 50\% reduction in periosteal bone callus formation at the cortical bone junction (Wang et al., 2010). BMP-2 and BMP-4 are also expressed in the chondrocytes of the healing callus and thickened periosteum near the fracture ends overlapping the Ihh-expressing cells (Onishi et al., 1998; Vortkamp et al., 1998), suggesting Ihh could regulate the osteoblast differentiation of periosteum and activate the early process 
of intramembranous bone formation independently or by a mechanism involving BMPs during fracture repair.

PTHrP is a member of a small parathyroid hormone (PTH) gene family (Wysolmerski et al., 1998). The PTHrP acts as predominantly a paracrine regulatory molecule while PTH acts as a classical systemic peptide hormone (Abou-Samra et al., 1992; Wysolmerski et al., 1998). Known functions of PTHrP include regulation of the chondrocyte differentiation program during development, mediating tooth eruption, mobilizing bone mineral from the skeleton during lactation, and endochondral bone formation (Juppner et al., 1991; Abou-Samra et al., 1992; Philbrick et al., 1998). PTHrP may also act directly on osteoblasts, but it does not directly stimulate osteogenic cell differentiation but stimulates proliferation (Miao et al., 2001). By means of a PTHrP-lacZ reporter mouse, PTHrP expression was identified in the fibrous layer of the periosteum (Chen et al., 2006). A mouse fracture model showed that $\mathrm{PTH} / \mathrm{PTHrP}$ receptor is strongly expressed in the periosteum at the site of the fracture by day 3 following fracture (Vortkamp et al., 1998). Conditionally deleting PTHrP from the perichondrial cells in the fibrous periosteum via the scleraxis gene (Scx-Cre) revealed impaired repair and delayed callus mineralization, and this PTHrP cKO compromised osteogenesis and osteoclastogenesis possibly through impaired BMP and TGF signaling. Interestingly, PTHrP cKO mice had increased Ihh gene expression in the callus (Wang et al., 2015a). These suggest that Ihh and PTHrP seem to play complementary roles in fracture healing, and there is functional cross talk integrating the BMP and Ihh/PTHrP signaling in the regulation of osteoblastic differentiation and proliferation during the bone healing process.

\section{IGF-1/PI3K-Akt signaling pathway}

Insulin-like growth factor 1 (IGF-1) is a major growth-promoting signal for the skeletal development of vertebrates (Baker et al., 1993). The IGF family includes two specific ligands IGF-1 and IGF-2, which bind and phosphorylate the membrane IGF-1 receptor (IGF-1R) to activate RAS/MAP and PI3-kinase/Akt kinase pathways leading to osteoblast differentiation and proliferation. The binding of Insulin-like growth factor 1 (IGF-1) to its receptor triggers the activation of several intracellular kinases, including phosphatidylinositol-3-kinase (PI3K). PI3K phosphorylates the membrane phospholipid phosphatidylinositol-4,5-bisphosphate to phosphatidylinositol 3,4,5 trisphosphate, recruiting PDK1 (a Ser/Thr kinase), which can phosphorylate and activate protein kinase B (AKT) (Cantley, 2002; Tahimic et al., 2013). Active AKT accelerates osteoblast differentiation by two transcription factors, Runx 2 and osterix, which acts via synergize with the Wnt-beta catenin pathway (Raucci et al., 2008). IGF-1 and IGF-1R increase locally in the fracture callus of patients, and their expression is markedly increased in the multi-layered periosteal cells in the developing bony calluses (Andrew et al., 1993; Okazaki et al., 2003). Low IGF-1 might be one of the pathophysiological mechanisms determining delayed or failed fracture healing in patients (Weiss et al., 2008). Conditional deletion of IGF-1R using Osterix Cre in early osteoprogenitor cells decreased osteoblast proliferation and differentiation and led to decreased bone mass and mineral deposition rates (Xian et al., 2012; Wang et al., 2015c). The use of the $2.3-\mathrm{kb}$ colla1 Cre promoter to delete the IGF1R in early differentiating osteoblasts contributed to the attenuation of osteoblast differentiation and lower bone 
volume accompanied by a defect in mineralization and bone microarchitectural abnormalities in a mouse nonstabilized tibial fracture model (Wang et al., 2015b). All the data from these studies show that activating IGF-1 signaling plays an essential role in stimulating the differentiation and proliferation of osteoblast progenitors. It is important to investigate the role of IGF-1 in periosteal cells by targeting osteochondroprogenitor-specific IGF-1 and IGF1R deletion utilizing Prx1-Cre or other markers/Cre drivers expressed in perichondrium/periosteum. This will enable us to understand the role of IGF-1 signaling in regulating chondro/osteo progenitor cells during fracture healing.

\section{The Effect of Biochemical and Biophysical Factors}

\section{Hypoxia and hyperoxia}

During the course of fracture healing, occlusion of the local circulation results in tissue anoxia and accumulation of carbon dioxide (Kivisaari and Niinikoski, 1975) with pO2 in the fracture hematoma reduced to <1\% (Brighton and Krebs, 1972). The local oxygen tension is believed to influence the differentiation of mesenchymal cells, with low oxygen tensions promoting the differentiation of mesenchymal cells along a chondrocyte pathway in part by activating Sox-9 via a HIF-1alpha-dependent mechanism (Robins et al., 2005). But the findings of Sheehy et al. (2012) showed that a low oxygen tension (5\% pO2) during expansion and differentiation enhances osteogenesis of bone marrow derived MSCs, whereas it seems that a lower oxygen tension (3\% pO2) could inhibit osteogenesis of bone marrow derived MSCs (D'Ippolito et al., 2006) and the effect of $2 \%$ oxygen tension reduced the Alkaline phosphatase activity and RNA expression as well as Runx2 expression in the human pre-osteoblastic cell line SV-HFO (Nicolaije et al., 2012). However, some results from vivo research are not consistent with these in vitro findings. A mouse tibia fracture study showed that environmental hypoxia (13\% pO2) inhibits fracture healing, while environmental hyperoxia (50\% pO2) also appeared to negatively impact fracture healing $(\mathrm{Lu}$ et al., 2013). On the other hand mice exposed to hyperbaric hyperoxia (HBO) after an open femur fracture showed significantly better femur fracture healing possibly through stimulating bone anabolism and osteoblast proliferation (Kawada et al., 2013). Most studies on the effect of oxygen tension on osteogenesis of MSCs used bone marrow-derived MSCs or an osteoblastic cell line instead of using the periosteal cells, which directly participate in fracture healing. One study cultured rat periosteal cells under hypoxic and normal conditions and found that hypoxic conditions could activate the osteogenic capability of periosteal cells exhibiting a stronger expression of HIF1a, VEGF, BMP2, Runx2, ALP, and BSP at the protein level. Clearly oxygen tension plays an important role in the differentiation of the stem cells at the fracture site. But based on current research, it is still unclear if and how the local oxygen tension regulates osteogenic differentiation and proliferation during fracture healing. More studies are needed to support the clinical use of hyperbaric oxygen in fracture healing.

\section{Reactive oxygen species (ROS)}

ROS are generated as part of normal aerobic life. Cellular ROS production is from mitochondrial oxidative phosphorylation and NADPH oxidase. ROS are formed as necessary intermediates in a variety of enzyme reactions, and are involved in signal transduction 
pathways (Finkel and Holbrook, 2000) and gene expression (Boopathy et al., 2013).

However unregulated levels of ROS are harmful, which lead to the induction of apoptosis (Martindale and Holbrook, 2002). Some reports suggested that ROS may be involved in the proliferation of osteoprogenitors and their subsequent differentiation (Imhoff and Hansen, 2011; Sun et al., 2013). The ROS level is increased after fracture, and oxidative stress may be proportional to the number of bones fractured (Turgut et al., 1999; Prasad et al., 2003). There is growing evidence that ROS levels influence the fracture healing process. Alcohol exposure induces oxidative stress and impairs fracture healing. Administration of $\mathrm{N}$ acetylcysteine, an antioxidant, improved endochondral ossification during fracture healing in alcohol-treated animals (Volkmer et al., 2011). Vitamin E (a-tocopherol), antioxidant in nature, improved fracture healing during the early callous formation phase. The improvement in fracture healing may be due to the increased activities of the anti-oxidatant enzymes (Shuid et al., 2011). ROS levels also affect cell survival. High levels can activate signaling pathways that lead to the induction of apoptosis. Oxidative stress inhibits the Wnt pathway and downregulates beta-catenin in osteoblast precursors by shifting beta-catenin activity toward FoxO and away from binding to the canonical Wnt transcription factor TCF (Shin et al., 2004; Almeida et al., 2007). Oxidative stress also inhibits Hedgehog signaling induced osteogenic differentiation in murine primary bone marrow-derived and other MSC cell lines (Kim et al., 2010), while osteogenic induction in osteoblast precursor cell lines resulting in enhancement of mineralization and expression of the osteogenic marker alkaline phosphatase was accompanied by an increase in ROS production (Arakaki et al., 2013). More studies are needed to investigate the specific role of ROS in the osteogenesis and osteoblast differentiation during fracture healing. Modulation of ROS could possibly serve a dual function: antioxidation could help reduce oxidative injury during the early period of fracture healing, and then an appropriate induction of ROS by manipulation of redox levels may have positive effects on bone mineralization during the stage of hard callus formation because ROS is actively involved in the regulation of apoptosis, which has also been shown to participate in the differentiation of the cells to the mature osteoblast phenotype and the onset of mineralization (Lynch et al., 1998).

\section{Conclusion}

Fracture healing is a complex physiological process which involves a well-orchestrated series of biological events. Ongoing research in this field of medicine has improved our understanding of fracture healing at the cellular and the molecular level. Our data and that of other researchers are revealing the skeletal progenitor sources for fracture repair, identifying the molecular pathways as well as physical and chemical factors controlling chondrocyte and osteoblast differentiation, and applying this knowledge to bone regenerative medicine and bone tissue engineering approaches. The aim of this review article is to characterize the complex and interacting mechanisms contributing to the fracture healing process in order to enhance the researchers' awareness of the complexity of skeletal progenitor origins, signaling pathways, physical and chemical factors, and the interactions between these factors during fracture repair. With the increasing understanding of the key skeletal progenitor sources and signaling pathways regulating bone forming cells, it is hoped that 
many bone diseases secondary to trauma, aging and metabolic disorders will be successfully treated with novel therapies.

\section{Acknowledgments}

This work was supported by NIH grant RO1AR055924, RO1AR0708840, AR067859, DE026256, DE019902, and a VA Program Project Award VA IPIBX001599. Institutional support was provided by Northern California Institute for Research and Education and by Center for Musculoskeletal Research, University of Rochester. The authors would like to thank Alicia Menendez, BS for assisting with the preparation of animal breeding.

Contract grant sponsor: NIH, VA Program Project Award; Contract grant numbers: RO1AR055924, RO1AR0708840, AR067859, DE026256, DE019902, VA IPIBX001599.

\section{Literature Cited}

Abou-Samra AB, Juppner H, Force T, Freeman MW, Kong XF, Schipani E, Urena P, Richards J, Bonventre JV, Potts JJ, Et A. Expression cloning of a common receptor for parathyroid hormone and parathyroid hormone-related peptide from rat osteoblast-like cells: A single receptor stimulates intracellular accumulation of both cAMP and inositol trisphosphates and increases intracellular free calcium. Proc Natl Acad Sci USA. 1992; 89:2732-2736. [PubMed: 1313566]

Akiyama H, Kim JE, Nakashima K, Balmes G, Iwai N, Deng JM, Zhang Z, Martin JF, Behringer RR, Nakamura T, de Crombrugghe B. Osteo-chondroprogenitor cells are derived from Sox 9 expressing precursors. Proc Natl Acad Sci USA. 2005; 102:14665-14670. [PubMed: 16203988]

Almeida M, Han L, Martin-Millan M, O’Brien CA, Manolagas SC. Oxidative stress antagonizes Wnt signaling in osteoblast precursors by diverting beta-catenin from $\mathrm{T}$ cell factor- to forkhead box Omediated transcription. J Biol Chem. 2007; 282:27298-27305. [PubMed: 17623658]

Andrew JG, Hoyland J, Freemont AJ, Marsh D. Insulinlike growth factor gene expression in human fracture callus. Calcif Tissue Int. 1993; 53:97-102. [PubMed: 8402329]

Arakaki N, Yamashita A, Niimi S, Yamazaki T. Involvement of reactive oxygen species in osteoblastic differentiation of MC3T3-E1 cells accompanied by mitochondrial morphological dynamics. Biomed Res. 2013; 34:161-166. [PubMed: 23782750]

Aubin, J., Triffitt, J. Mesenchymal stem cells and osteoblast differentiation. In: Bilezikian, J.Raisz, LG., Rodan, GA., editors. Principles of bone biology. San Diego: Academic Press; 2002. p. 59-81.

Baker J, Liu JP, Robertson EJ, Efstratiadis A. Role of insulin-like growth factors in embryonic and postnatal growth. Cell. 1993; 75:73-82. [PubMed: 8402902]

Boopathy AV, Pendergrass KD, Che PL, Yoon YS, Davis ME. Oxidative stress-induced Notch1 signaling promotes cardiogenic gene expression in mesenchymal stem cells. Stem Cell Res Ther. 2013; 4:43. [PubMed: 23597145]

Brighton CT, Krebs AG. Oxygen tension of healing fractures in the rabbit. J Bone Joint Surg Am. 1972; 54:323-332. [PubMed: 4651264]

Cantley LC. The phosphoinositide 3-kinase pathway. Science. 2002; 296:1655-1657. [PubMed: 12040186]

Chen X, Macica CM, Dreyer BE, Hammond VE, Hens JR, Philbrick WM, Broadus AE. Initial characterization of PTH-related protein gene-driven lacZ expression in the mouse. J Bone Miner Res. 2006; 21:113-123. [PubMed: 16355280]

Chen Y, Whetstone HC, Lin AC, Nadesan P, Wei Q, Poon R, Alman BA. Beta-catenin signaling plays a disparate role in different phases of fracture repair: Implications for therapy to improve bone healing. PLoS Med. 2007; 4:e249. [PubMed: 17676991]

Chen G, Deng C, Li YP. TGF-beta and BMP signaling in osteoblast differentiation and bone formation. Int J Biol Sci. 2012; 8:272-288. [PubMed: 22298955]

Cho TJ, Gerstenfeld LC, Einhorn TA. Differential temporal expression of members of the transforming growth factor beta superfamily during murine fracture healing. J Bone Miner Res. 2002; 17:513520. [PubMed: 11874242] 
Clevers H. Wnt/beta-catenin signaling in development and disease. Cell. 2006; 127:469-480. [PubMed: 17081971]

Colnot C. Skeletal cell fate decisions within periosteum and bone marrow during bone regeneration. $\mathrm{J}$ Bone Miner Res. 2009; 24:274-282. [PubMed: 18847330]

D’Ippolito G, Diabira S, Howard GA, Roos BA, Schiller PC. Low oxygen tension inhibits osteogenic differentiation and enhances stemness of human MIAMI cells. Bone. 2006; 39:513-522. [PubMed: 16616713]

Diaz-Flores L, Gutierrez R, Lopez-Alonso A, Gonzalez R, Varela H. Pericytes as a supplementary source of osteoblasts in periosteal osteogenesis. Clin Orthop Relat Res. 1992; 275:280-286.

Dominici M, Marino R, Rasini V, Spano C, Paolucci P, Conte P, Hofmann TJ, Horwitz EM. Donor cell-derived osteopoiesis originates from a self-renewing stem cell with a limited regenerative contribution after transplantation. Blood. 2008; 111:4386-4391. [PubMed: 18182575]

Dwek JR. The periosteum: What is it, where is it, and what mimics it in its absence? Skeletal Radiol. 2010; 39:319-323. [PubMed: 20049593]

Finkel T, Holbrook NJ. Oxidants, oxidative stress and the biology of ageing. Nature. 2000; 408:239247. [PubMed: 11089981]

Gaur T, Lengner CJ, Hovhannisyan H, Bhat RA, Bodine PV, Komm BS, Javed A, van Wijnen AJ, Stein JL, Stein GS, Lian JB. Canonical WNT signaling promotes osteogenesis by directly stimulating Runx2 gene expression. J Biol Chem. 2005; 280:33132-33140. [PubMed: 16043491]

Gaur T, Wixted JJ, Hussain S, O'Connell SL, Morgan EF, Ayers DC, Komm BS, Bodine PV, Stein GS, Lian JB. Secreted frizzled related protein 1 is a target to improve fracture healing. J Cell Physiol. 2009; 220:174-181. [PubMed: 19301255]

Hill TP, Spater D, Taketo MM, Birchmeier W, Hartmann C. Canonical Wnt/beta-catenin signaling prevents osteoblasts from differentiating into chondrocytes. Dev Cell. 2005; 8:727-738. [PubMed: 15866163]

Hohmann EL, Elde RP, Rysavy JA, Einzig S, Gebhard RL. Innervation of periosteum and bone by sympathetic vasoactive intestinal peptide-containing nerve fibers. Science. 1986; 232:868-871. [PubMed: 3518059]

Horbelt D, Denkis A, Knaus P. A portrait of Transforming Growth Factor beta superfamily signalling: Background matters. Int J Biochem Cell Biol. 2012; 44:469-474. [PubMed: 22226817]

Huang C, Xue M, Chen H, Jiao J, Herschman HR, O'Keefe RJ, Zhang X. The spatiotemporal role of COX-2 in osteogenic and chondrogenic differentiation of periosteum-derived mesenchymal progenitors in fracture repair. PLoS ONE. 2014; 9:e100079. [PubMed: 24988184]

Imhoff B, Hansen J. Differential redox potential profiles during adipogenesis and osteogenesis. Cell Mol Biol Lett. 2011; 16:149-161. [PubMed: 21225471]

Israel DI, Nove J, Kerns KM, Kaufman RJ, Rosen V, Cox KA, Wozney JM. Heterodimeric bone morphogenetic proteins show enhanced activity in vitro and in vivo. Growth Factors. 1996; 13:291-300. [PubMed: 8919035]

Jin H, Wang B, Li J, Xie W, Mao Q, Li S, Dong F, Sun Y, Ke HZ, Babij P, Tong P, Chen D. AntiDKK1 antibody promotes bone fracture healing through activation of beta-catenin signaling. Bone. 2015; 71:63-75. [PubMed: 25263522]

Joyce ME, Roberts AB, Sporn MB, Bolander ME. Transforming growth factor-beta and the initiation of chondrogenesis and osteogenesis in the rat femur. J Cell Biol. 1990; 110:2195-2207. [PubMed: 2351696]

Juppner H, Abou-Samra AB, Freeman M, Kong XF, Schipani E, Richards J, Kolakowski LJ, Hock J, Potts JJ, Kronenberg HM, Et A. A G protein-linked receptor for parathyroid hormone and parathyroid hormone-related peptide. Science. 1991; 254:1024-1026. [PubMed: 1658941]

Kalajzic Z, Li H, Wang LP, Jiang X, Lamothe K, Adams DJ, Aguila HL, Rowe DW, Kalajzic I. Use of an alpha-smooth muscle actin GFP reporter to identify an osteoprogenitor population. Bone. 2008; 43:501-510. [PubMed: 18571490]

Kawada S, Wada E, Matsuda R, Ishii N. Hyperbaric hyperoxia accelerates fracture healing in mice. PLoS ONE. 2013; 8:e72603. [PubMed: 23967323] 
Kawanami A, Matsushita T, Chan YY, Murakami S. Mice expressing GFP and CreER in osteochondro progenitor cells in the periosteum. Biochem Biophys Res Commun. 2009; 386:477-482. [PubMed: 19538944]

Kim WK, Meliton V, Bourquard N, Hahn TJ, Parhami F. Hedgehog signaling and osteogenic differentiation in multipotent bone marrow stromal cells are inhibited by oxidative stress. J Cell Biochem. 2010; 111:1199-1209. [PubMed: 20717924]

Kim JH, Liu X, Wang J, Chen X, Zhang H, Kim SH, Cui J, Li R, Zhang W, Kong Y, Zhang J, Shui W, Lamplot J, Rogers MR, Zhao C, Wang N, Rajan P, Tomal J, Statz J, Wu N, Luu HH, Haydon RC, He TC. Wnt signaling in bone formation and its therapeutic potential for bone diseases. Ther Adv Musculoskelet Dis. 2013; 5:13-31. [PubMed: 23514963]

Kivisaari J, Niinikoski J. Tissue oxygen and carbon dioxide tensions in healing rabbit tibias. Acta Orthop Scand. 1975; 46:269-279. [PubMed: 1146519]

Le AX, Miclau T, Hu D, Helms JA. Molecular aspects of healing in stabilized and non-stabilized fractures. J Orthop Res. 2001; 19:78-84. [PubMed: 11332624]

Lerner RK, Esterhai JJ, Polomano RC, Cheatle MD, Heppenstall RB. Quality of life assessment of patients with posttraumatic fracture nonunion, chronic refractory osteomyelitis, and lowerextremity amputation. Clin Orthop Relat Res. 1993; 295:28-36.

Levy L, Wei Y, Labalette C, Wu Y, Renard CA, Buendia MA, Neuveut C. Acetylation of beta-catenin by p300 regulates beta-catenin-Tcf4 interaction. Mol Cell Biol. 2004; 24:3404-3414. [PubMed: 15060161]

Lu C, Saless N, Wang X, Sinha A, Decker S, Kazakia G, Hou H, Williams B, Swartz HM, Hunt TK, Miclau T, Marcucio RS. The role of oxygen during fracture healing. Bone. 2013; 52:220-229. [PubMed: 23063782]

Lynch MP, Capparelli C, Stein JL, Stein GS, Lian JB. Apoptosis during bone-like tissue development in vitro. J Cell Biochem. 1998; 68:31-49. [PubMed: 9407312]

Macsai CE, Foster BK, Xian CJ. Roles of Wnt signalling in bone growth, remodelling, skeletal disorders and fracture repair. J Cell Physiol. 2008; 215:578-587. [PubMed: 18247365]

Mao J, Wang J, Liu B, Pan W, Farr GR, Flynn C, Yuan H, Takada S, Kimelman D, Li L, Wu D. Lowdensity lipoprotein receptor-related protein-5 binds to Axin and regulates the canonical Wnt signaling pathway. Mol Cell. 2001; 7:801-809. [PubMed: 11336703]

Martin JF, Olson EN. Identification of a prx1 limb enhancer. Genesis. 2000; 26:225-229. [PubMed: 10748458]

Martin JF, Bradley A, Olson EN. The paired-like homeo box gene MHox is required for early events of skeletogenesis in multiple lineages. Genes Dev. 1995; 9:1237-1249. [PubMed: 7758948]

Martindale JL, Holbrook NJ. Cellular response to oxidative stress: Signaling for suicide and survival. J Cell Physiol. 2002; 192:1-15. [PubMed: 12115731]

Matsunobu T, Torigoe K, Ishikawa M, de Vega S, Kulkarni AB, Iwamoto Y, Yamada Y. Critical roles of the TGF-beta type I receptor ALK5 in perichondrial formation and function, cartilage integrity, and osteoblast differentiation during growth plate development. Dev Biol. 2009; 332:325-338. [PubMed: 19501582]

Matthews BG, Grcevic D, Wang L, Hagiwara Y, Roguljic H, Joshi P, Shin D, Adams DJ, Kalajzic I. Analysis of aSMA-labeled progenitor cell commitment identifies notch signaling as an important pathway in fracture healing. J Bone Miner Res. 2014; 29:1283-1294. [PubMed: 24190076]

Miao D, Tong XK, Chan GK, Panda D, McPherson PS, Goltzman D. Parathyroid hormone-related peptide stimulates osteogenic cell proliferation through protein kinase $\mathrm{C}$ activation of the Ras/ mitogen-activated protein kinase signaling pathway. J Biol Chem. 2001; 276:32204-32213. [PubMed: 11402023]

Nakahara H, Bruder SP, Goldberg VM, Caplan AI. In vivo osteochondrogenic potential of cultured cells derived from the periosteum. Clin Orthop Relat Res. 1990; 259:223-232.

Nicolaije C, Koedam M, van Leeuwen JP. Decreased oxygen tension lowers reactive oxygen species and apoptosis and inhibits osteoblast matrix mineralization through changes in early osteoblast differentiation. J Cell Physiol. 2012; 227:1309-1318. [PubMed: 21604266] 
Okazaki K, Jingushi S, Ikenoue T, Urabe K, Sakai H, Iwamoto Y. Expression of parathyroid hormonerelated peptide and insulin-like growth factor I during rat fracture healing. J Orthop Res. 2003; 21:511-520. [PubMed: 12706025]

Onishi T, Ishidou Y, Nagamine T, Yone K, Imamura T, Kato M, Sampath TK, Ten DP, Sakou T. Distinct and overlapping patterns of localization of bone morphogenetic protein (BMP) family members and a BMP type II receptor during fracture healing in rats. Bone. 1998; 22:605-612. [PubMed: 9626398]

Ornitz DM, Marie PJ. FGF signaling pathways in endochondral and intramembranous bone development and human genetic disease. Genes Dev. 2002; 16:1446-1465. [PubMed: 12080084]

Park D, Spencer JA, Koh BI, Kobayashi T, Fujisaki J, Clemens TL, Lin CP, Kronenberg HM, Scadden DT. Endogenous bone marrow MSCs are dynamic, fate-restricted participants in bone maintenance and regeneration. Cell Stem Cell. 2012; 10:259-272. [PubMed: 22385654]

Philbrick WM, Dreyer BE, Nakchbandi IA, Karaplis AC. Parathyroid hormone-related protein is required for tooth eruption. Proc Natl Acad Sci USA. 1998; 95:11846-11851. [PubMed: 9751753]

Praemer, A., Furner, S., Rice, D. Musculoskeletal conditions in the United States. Park Ridge, IL: American Academy of Orthopaedic Surgeons; 1992. p. 83

Prasad G, Dhillon MS, Khullar M, Nagi ON. Evaluation of oxidative stress after fractures. A preliminary study. Acta Orthop Belg. 2003; 69:546-551. [PubMed: 14748113]

Quarto N, Behr B, Longaker MT. Opposite spectrum of activity of canonical Wnt signaling in the osteogenic context of undifferentiated and differentiated mesenchymal cells: Implications for tissue engineering. Tissue Eng Part A. 2010; 16:3185-3197. [PubMed: 20590472]

Raucci A, Bellosta P, Grassi R, Basilico C, Mansukhani A. Osteoblast proliferation or differentiation is regulated by relative strengths of opposing signaling pathways. J Cell Physiol. 2008; 215:442-451. [PubMed: 17960591]

Rieger K, Marinets O, Fietz T, Korper S, Sommer D, Mucke C, Reufi B, Blau WI, Thiel E, Knauf WU. Mesenchymal stem cells remain of host origin even a long time after allogeneic peripheral blood stem cell or bone marrow transplantation. Exp Hematol. 2005; 33:605-611. [PubMed: 15850839]

Robins JC, Akeno N, Mukherjee A, Dalal RR, Aronow BJ, Koopman P, Clemens TL. Hypoxia induces chondrocyte-specific gene expression in mesenchymal cells in association with transcriptional activation of Sox9. Bone. 2005; 37:313-322. [PubMed: 16023419]

Rodriguez-Carballo E, Gamez B, Ventura F. P38 MAPK signaling in osteoblast differentiation. Front Cell Dev Biol. 2016; 4:40. [PubMed: 27200351]

Roguljic H, Matthews BG, Yang W, Cvija H, Mina M, Kalajzic I. In vivo identification of periodontal progenitor cells. J Dent Res. 2013; 92:709-715. [PubMed: 23735585]

Ross SE, Hemati N, Longo KA, Bennett CN, Lucas PC, Erickson RL, MacDougald OA. Inhibition of adipogenesis by Wnt signaling. Science. 2000; 289:950-953. [PubMed: 10937998]

Ryoo HM, Lee MH, Kim YJ. Critical molecular switches involved in BMP-2-induced osteogenic differentiation of mesenchymal cells. Gene. 2006; 366:51-57. [PubMed: 16314053]

Sakou T. Bone morphogenetic proteins: From basic studies to clinical approaches. Bone. 1998; 22:591-603. [PubMed: 9626397]

Sakurai H. Targeting of TAK1 in inflammatory disorders and cancer. Trends Pharmacol Sci. 2012; 33:522-530. [PubMed: 22795313]

Seo HS, Serra R. Deletion of Tgfbr2 in Prx1-cre expressing mesenchyme results in defects in development of the long bones and joints. Dev Biol. 2007; 310:304-316. [PubMed: 17822689]

Sheehy EJ, Buckley CT, Kelly DJ. Oxygen tension regulates the osteogenic, chondrogenic and endochondral phenotype of bone marrow derived mesenchymal stem cells. Biochem Bioph Res Co. 2012; 417:305-310.

Shin SY, Kim CG, Jho EH, Rho MS, Kim YS, Kim YH, Lee YH. Hydrogen peroxide negatively modulates Wnt signaling through downregulation of beta-catenin. Cancer Lett. 2004; 212:225231. [PubMed: 15279902]

Shuid AN, Mohamad S, Muhammad N, Fadzilah FM, Mokhtar SA, Mohamed N, Soelaiman IN. Effects of alpha-tocopherol on the early phase of osteoporotic fracture healing. J Orthop Res. 2011; 29:1732-1738. [PubMed: 21547940] 
Silkstone D, Hong H, Alman BA. Beta-catenin in the race to fracture repair: In it to Wnt. Nat Clin Pract Rheumatol. 2008; 4:413-419. [PubMed: 18560386]

Squier CA, Ghoneim S, Kremenak CR. Ultrastructure of the periosteum from membrane bone. J Anat. 1990; 171:233-239. [PubMed: 2081707]

St-Jacques B, Hammerschmidt M, McMahon AP. Indian hedgehog signaling regulates proliferation and differentiation of chondrocytes and is essential for bone formation. Genes Dev. 1999; 13:2072-2086. [PubMed: 10465785]

Sun N, Yang L, Li Y, Zhang H, Chen H, Liu D, Li Q, Cai D. Effect of advanced oxidation protein products on the proliferation and osteogenic differentiation of rat mesenchymal stem cells. Int $\mathbf{J}$ Mol Med. 2013; 32:485-491. [PubMed: 23722883]

Tachi K, Takami M, Sato H, Mochizuki A, Zhao B, Miyamoto Y, Tsukasaki H, Inoue T, Shintani S, Koike T, Honda Y, Suzuki O, Baba K, Kamijo R. Enhancement of bone morphogenetic protein-2induced ectopic bone formation by transforming growth factor-beta1. Tissue Eng Part A. 2011; 17:597-606. [PubMed: 20874259]

Tahimic CG, Wang Y, Bikle DD. Anabolic effects of IGF-1 signaling on the skeleton. Front Endocrinol (Lausanne). 2013; 4:6. [PubMed: 23382729]

Tsuji K, Bandyopadhyay A, Harfe BD, Cox K, Kakar S, Gerstenfeld L, Einhorn T, Tabin CJ, Rosen V. BMP2 activity, although dispensable for bone formation, is required for the initiation of fracture healing. Nat Genet. 2006; 38:1424-1429. [PubMed: 17099713]

Turgut A, Gokturk E, Kose N, Kacmaz M, Ozturk HS, Seber S, Acar S. Oxidant status increased during fracture healing in rats. Acta Orthop Scand. 1999; 70:487-490. [PubMed: 10622483]

Volkmer DL, Sears B, Lauing KL, Nauer RK, Roper PM, Yong S, Stover M, Callaci JJ. Antioxidant therapy attenuates deficient bone fracture repair associated with binge alcohol exposure. J Orthop Trauma. 2011; 25:516-521. [PubMed: 21738068]

Vortkamp A, Lee K, Lanske B, Segre GV, Kronenberg HM, Tabin CJ. Regulation of rate of cartilage differentiation by Indian hedgehog and PTH-related protein. Science. 1996; 273:613-622. [PubMed: 8662546]

Vortkamp A, Pathi S, Peretti GM, Caruso EM, Zaleske DJ, Tabin CJ. Recapitulation of signals regulating embryonic bone formation during postnatal growth and in fracture repair. Mech Dev. 1998; 71:65-76. [PubMed: 9507067]

Waki T, Lee SY, Niikura T, Iwakura T, Dogaki Y, Okumachi E, Oe K, Kuroda R, Kurosaka M. Profiling microRNA expression during fracture healing. BMC Musculoskelet Disord. 2016; 17:83. [PubMed: 26879131]

Wang EA, Israel DI, Kelly S, Luxenberg DP. Bone morphogenetic protein-2 causes commitment and differentiation in C3H10T1/2 and 3T3 cells. Growth Factors. 1993; 9:57-71. [PubMed: 8347351]

Wang Q, Huang C, Zeng F, Xue M, Zhang X. Activation of the Hh pathway in periosteum-derived mesenchymal stem cells induces bone formation in vivo. Am J Pathol. 2010; 177:3100-3111. [PubMed: 20971735]

Wang Q, Huang C, Xue M, Zhang X. Expression of endogenous BMP-2 in periosteal progenitor cells is essential for bone healing. Bone. 2011; 48:524-532. [PubMed: 21056707]

Wang M, Nasiri AR, Broadus AE, Tommasini SM. Periosteal PTHrP regulates cortical bone remodeling during fracture healing. Bone. 2015a; 81:104-111. [PubMed: 26164475]

Wang T, Wang Y, Menendez A, Fong C, Babey M, Tahimic CG, Cheng Z, Li A, Chang W, Bikle DD. Osteoblast-Specific loss of IGF1R signaling results in impaired endochondral bone formation during fracture healing. J Bone Miner Res. 2015b; 30:1572-1584. [PubMed: 25801198]

Wang Y, Menendez A, Fong C, ElAlieh HZ, Kubota T, Long R, Bikle DD. IGF-I signaling in osterixExpressing cells regulates secondary ossification center formation, growth plate maturation, and metaphyseal formation during postnatal bone development. J Bone Miner Res. 2015c; 30:2239_ 2248. [PubMed: 26011431]

Weiss S, Henle P, Bidlingmaier M, Moghaddam A, Kasten P, Zimmermann G. Systemic response of the GH/IGF-I axis in timely versus delayed fracture healing. Growth Horm IGF Res. 2008; 18:205-212. [PubMed: 17936052]

Wysolmerski JJ, Philbrick WM, Dunbar ME, Lanske B, Kronenberg H, Broadus AE. Rescue of the parathyroid hormone-related protein knockout mouse demonstrates that parathyroid hormone- 
related protein is essential for mammary gland development. Development. 1998; 125:1285-1294. [PubMed: 9477327]

Xian L, Wu X, Pang L, Lou M, Rosen CJ, Qiu T, Crane J, Frassica F, Zhang L, Rodriguez JP, Jia X, Yakar S, Xuan S, Efstratiadis A, Wan M, Cao X. Matrix IGF-1 maintains bone mass by activation of mTOR in mesenchymal stem cells. Nat Med. 2012; 18:1095-1101. [PubMed: 22729283]

Yamaguchi A, Komori T, Suda T. Regulation of osteoblast differentiation mediated by bone morphogenetic proteins, hedgehogs, and Cbfa1. Endocr Rev. 2000; 21:393-411. [PubMed: 10950158]

Yang W, Guo D, Harris MA, Cui Y, Gluhak-Heinrich J, Wu J, Chen XD, Skinner C, Nyman JS, Edwards JR, Mundy GR, Lichtler A, Kream BE, Rowe DW, Kalajzic I, David V, Quarles DL, Villareal D, Scott G, Ray M, Liu S, Martin JF, Mishina Y, Harris SE. Bmp2 in osteoblasts of periosteum and trabecular bone links bone formation to vascularization and mesenchymal stem cells. J Cell Sci. 2013; 126:4085-4098. [PubMed: 23843612]

Yang L, Tsang KY, Tang HC, Chan D, Cheah KS. Hypertrophic chondrocytes can become osteoblasts and osteocytes in endochondral bone formation. Proc Natl Acad Sci USA. 2014; 111:1209712102. [PubMed: 25092332]

Yu K, Xu J, Liu Z, Sosic D, Shao J, Olson EN, Towler DA, Ornitz DM. Conditional inactivation of FGF receptor 2 reveals an essential role for FGF signaling in the regulation of osteoblast function and bone growth. Development. 2003; 130:3063-3074. [PubMed: 12756187]

Zhang F, Phiel CJ, Spece L, Gurvich N, Klein PS. Inhibitory phosphorylation of glycogen synthase kinase-3 (GSK-3) in response to lithium. Evidence for autoregulation of GSK-3. J Biol Chem. 2003; 278:33067-33077. [PubMed: 12796505]

Zhang X, Xie C, Lin AS, Ito H, Awad H, Lieberman JR, Rubery PT, Schwarz EM, O'Keefe RJ, Guldberg RE. Periosteal progenitor cell fate in segmental cortical bone graft transplantations: Implications for functional tissue engineering. J Bone Miner Res. 2005; 20:2124-2137. [PubMed: 16294266]

Zhang R, Oyajobi BO, Harris SE, Chen D, Tsao C, Deng HW, Zhao M. Wnt/beta-catenin signaling activates bone morphogenetic protein 2 expression in osteoblasts. Bone. 2013; 52:145-156. [PubMed: 23032104]

Zhou S. TGF-beta regulates beta-catenin signaling and osteoblast differentiation in human mesenchymal stem cells. J Cell Biochem. 2011; 112:1651-1660. [PubMed: 21344492] 

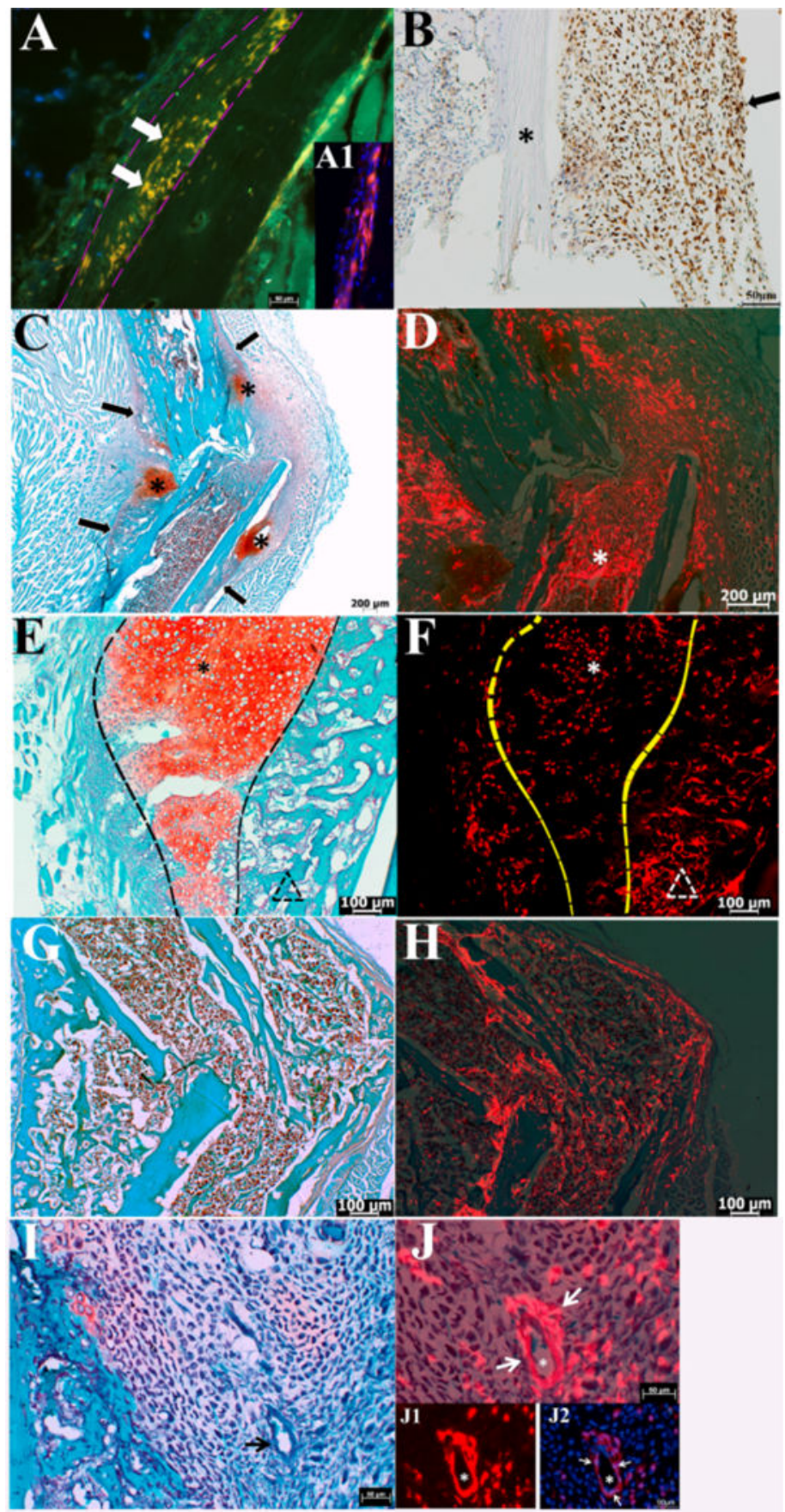

Fig. 1.

The analysis of the process of fracture healing with Tamoxifen inducible Prx1-CreEReGFPtdTomato transgenic mice. Following tamoxifenadministration to these mice, the fluorescent probe expressed in the cells originating from the periosteum show deep red fluorescence through a Texasred fluorescent filter (Texas filter) marking cells expressing tdTomato and their progeny as well as yellow fluorescence through a Calcein fluorescentfilter (Calcein filter) marking cells expressing both the tdTomato and eGFP fluorescence. A: The thickening of the cambial layer in the periosteumadjacent to the site of 
fracture at 1 day after fracture. The periosteal cells showed Prx1-eGFP-tdTomato-yellow fluorescence through the Calcein filter(white arrow). Low magnification of the local periosteum under Texas filter (A1) indicates Prx1-tdTomato-labeled red cells in the periosteal layer. Diaminophenylindole (DAPI)-labeled nuclei are blue. B: Periosteal reaction consisted of thick and dense proliferating cells detected byimmunohistochemical staining of proliferating cell nuclear antigen (PCNA) (black arrow) at the proximal end of broken cortical bone $(*)$ at 7 days afterfracture. C: Intramembranous bone formation initiated immediately adjacent to distal edges of the periosteal reaction (black arrow), while cartilageformation stained red with safranin $\mathrm{O}(*)$ usually occurred external to the periosteum at 5 days after fracture (Safranin-O/fast green stain). D: The sameslice of Figure $\mathrm{C}$ under Texas filter overlaid by the partial image of Figure $\mathrm{C}$ in Photoshop showed that the cells with red fluorescent protein (tdTomato)originated from the periosteum and migrated into the soft callus at 5 days after fracture, during which time the medullary cavity of endosteal boneformation $(*)$ was also formed. E: The cartilage callus within the gap underwent endochondral ossification, rich in chondrocyte cells stained red with safranin $\mathrm{O}$

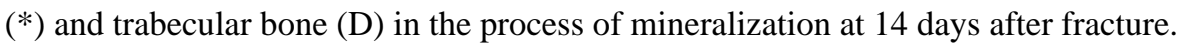
(Safranin-O/fast green stain). F: The same slice ofFigure E under Texas filter showed that most of cells in the regions of cartilage $(*)$ and trabecular bone (D) exhibited red fluorescence. G: The cartilagecallus disappeared at 21 days after fracture (Safranin-O/fast green stain). H: The same slice of Figure $G$ under Texas filter overlaid by the partial image ofFigure G in Photoshop showed that cells with red fluorescent protein (tdTomato) appeared on the surface of trabecular bone and within the trabecularbone structure in the calcified cartilage region. I: Vascular cavities (black arrow) were formed in the callus at 7 days after fracture (Safranin-O/fast green stain). J: The same slice of Figure I under Texas filter (J1) overlaid by the partial image of Figure I in Photoshop showed that many cells (white arrows)with red fluorescent protein (tdTomato) were detected on the wall of cavities $(*)$. Those cells (white arrows) had discoid nuclei labeled by DAPI (J2). 

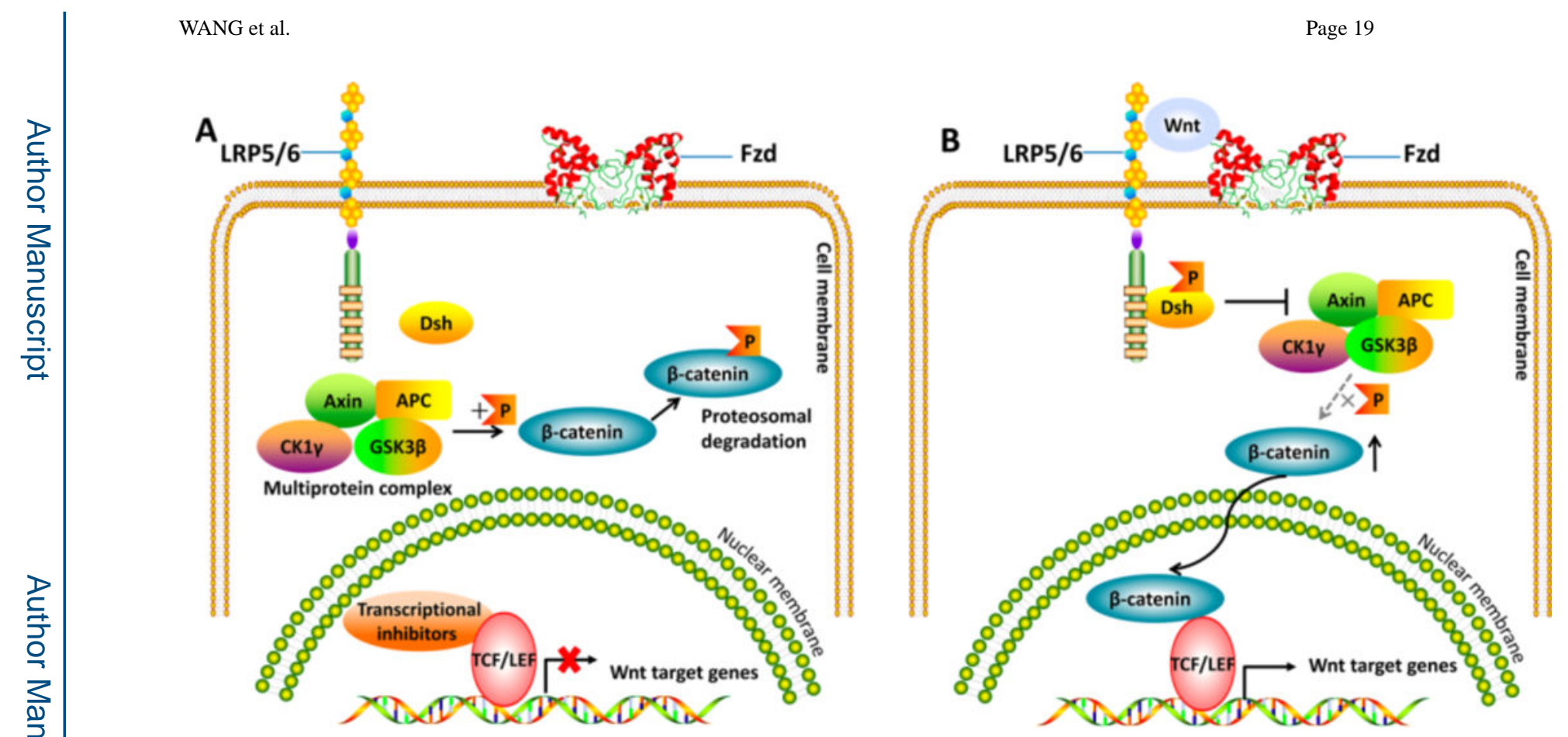

Fig. 2.

The canonical Wnt/b-catenin signaling pathway. A: In the absence of an activating Wnt ligand, cytoplasmic protein Dsh remains unphosphorylated. This in turn allows a multiprotein complex, which includes the scaffolding proteins APC and Axin, CK1g and GSK3b, to phosphorylate $b$ catenin and leads to its ubiquitination and proteasomal degradation. As a result, Wnt target gene expression is repressed by transcriptional inhibitors. B: In the presence of the Wnt ligand, the ligand binds to frizzled (Fzd) receptor and its coreceptor low-density lipoprotein receptor-related protein (LRP)-5/6, causing the phosphorylation of Dsh. Phosphorylated Dsh is subsequently activated, which inhibits GSK3b from phosphorylating $b$ catenin in the cytoplasm. $b$ catenin is stabilized and able to be translocated into the nucleus. b-catenin can then bind to TCF/LEF transcription factors, thereby regulating the expression of Wnt target genes. APC, adenomatous polyposis coli; CK1g, casein kinase 1g; Dsh, Dishevelled; GSK3b, glycogen synthase kinase 3b; Fzd, frizzled; LRP5/6, low density lipoprotein receptorrelated protein 5/6; TCF/LEF, T-cell factor/lymphocyte enhancer factor; P, phosphorylation (modified from Kim et al., 2013). 


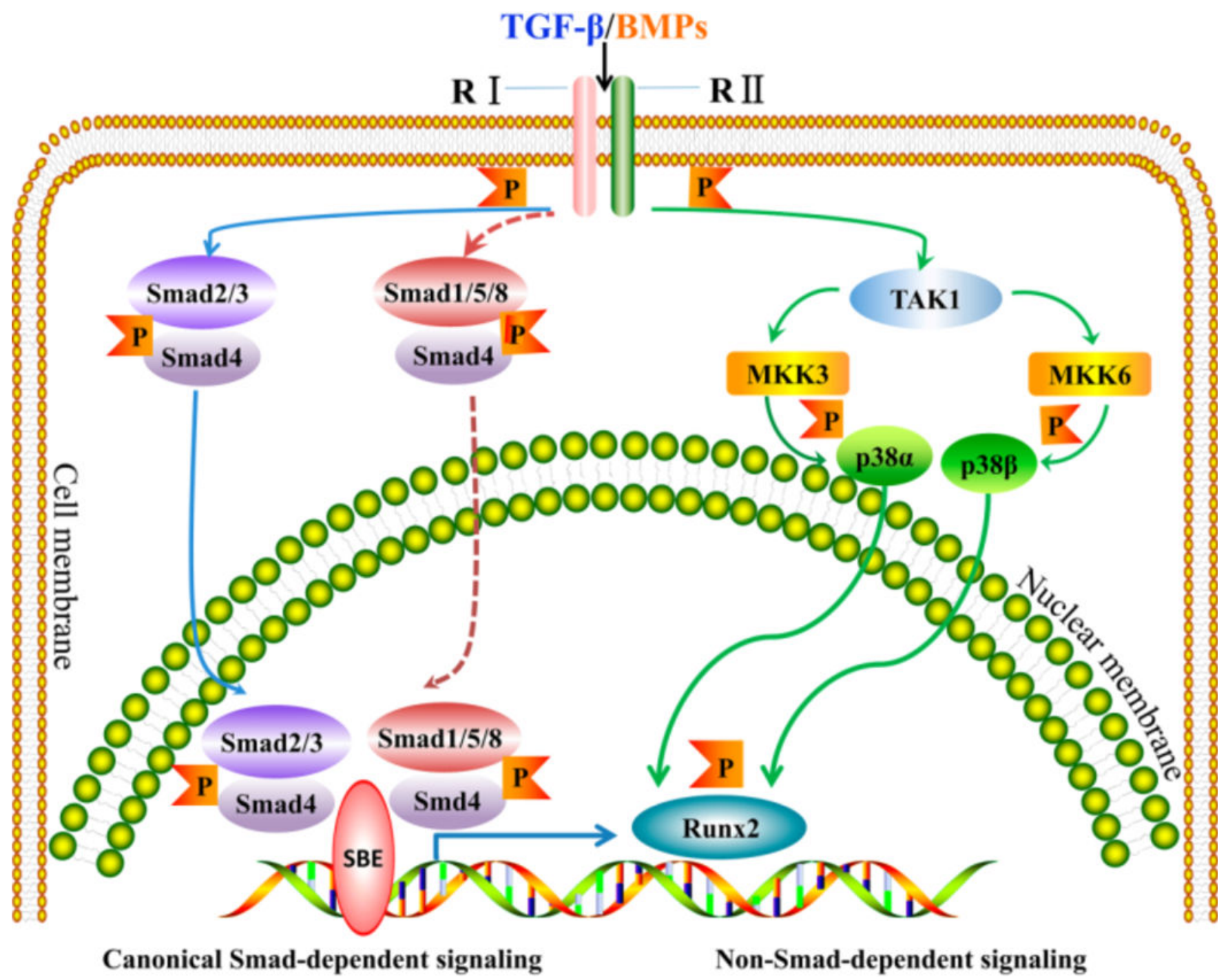

Fig. 3.

TGF-b/BMP signaling pathway in osteoblast differentiation. Canonical Smad-dependent TGF-b/BMPs signaling involves the binding of TGF-b/BMPs to receptor type I (RI) and receptor type II (R-II), and phosphorylation of cytoplasmic signaling molecules Smad2 and Smad3 for the TGF-b signaling pathway (solid line), or Smad1/5/9 for the bone morphogenetic protein (BMP) pathway (dash line). Theactivated Smads form a complex with Smad4 and translocate into the nucleus where they recognize the Smad-binding element (SBE) in the Runx2 gene promoter to trigger its expression. Moreover, the nonSmad-dependent TGF-b/BMPs signaling pathway (p38 MAPK) also regulates osteogenesis by activating TAK1 which phosphorylates MKK3/6. Activated p38 phosphorylates Runx2 and boosts its transcriptional potential. P, phosphorylation; SBE, Smad-binding element; MAPK, mitogen-activated protein kinase; TAK1, TGF-b activation kinase1; MKK3/6, mitogen-activated protein kinase kinase 3/6; Runx2, Runt Related Transcription Factor 2. 